Agata Komorowska Uniwersytet Jagielloński, Kraków agakomor@poczta.fm

\title{
EI distanciamiento del emisor frente a su propio mensaje
}

\begin{abstract}
:
Speaker's Distance Towards his own Enunciation

This paper approaches linguistic methods either grammatical or lexical, used by Spanish speaking participants of a communication act to express distance to their own enunciation.
\end{abstract}

Keywords: speaker, addressee, modality, multilevel discourse

\section{Streszczenie:}

Dystans nadawcy wobec wlasnej wypowiedzi

Artykuł przybliża środki językowe, czy to gramatyczne, czy też leksykalne, stosowane przez hiszpańskojęzycznych uczestników sytuacji komunikacyjnej w celu wyrażenia dystansu do własnej wypowiedzi.

Słowa kluczowe: nadawca, odbiorca, modalność, wielopoziomowość dyskursu 


\section{Introducción}

Es bien sabido que el uso de determinados recursos léxicos y gramaticales no sólo se rige por las reglas lingüísticas, sino que también está sometido a las elecciones subjetivas del hablante. Tales elecciones nunca son casuales, debido a que reflejan la postura del emisor del enunciado en cuestión y las diversas estrategias discursivas por las que apuesta este último para completar la significación de su mensaje.

Entre las actitudes que puede adoptar el hablante a la hora de transmitir un mensaje se encuentra su voluntad de distanciarse respecto a algún elemento de la situación comunicativa, como el mensaje mismo o los participantes del acto de habla. El objetivo del presente artículo es dar cuenta de los posibles métodos de dicho distanciamiento, tomando en consideración sólo los casos que afectan a enunciados enteros y no se limitan a uno de sus componentes, como ocurre en el uso de los demostrativos, capaces de expresar la lejanía o proximidad mental del hablante frente a una determinada unidad del enunciado.

\section{Distanciamiento frente al contenido}

Dos son generalmente las razones por las que el hablante decide señalar explícitamente su postura de distanciamiento hacia el mensaje que transmite. El primer caso se da cuando el emisor quiere manifestar su falta de seguridad en lo referente al contenido del mensaje. El segundo tiene lugar a la hora de presentar palabras de otras personas.

El primer tipo de distanciamiento hace referencia a la inseguridad y consiste en marcar una actitud poco comprometida con el contenido del mensaje. El hablante no pretende decidir si lo que dice es verdadero o todo lo contrario, ya que en realidad una y otra opción son posibles. Su intención es simplemente la de señalar que, por alguna razón, no se identifica con la información transmitida. 
El castellano ofrece al hablante varios recursos léxicos y gramaticales para expresar dudas acerca de los datos presentados. Si el emisor quiere distanciarse del enunciado, puede recurrir a uno de los numerosos giros de probabilidad (es probable que, es posible que, tal vez, quizás, etc.), reforzados en su mayoría por el uso del subjuntivo, como en el siguiente ejemplo:

\section{1) Es posible que mi vecina tenga novio.}

El modo subjuntivo tiene, de hecho, la capacidad de intensificar el distanciamiento del locutor hacia lo que dice. Existen casos en los que el mismo enunciado adquiere mayor certeza al emplearse el modo indicativo o suena como una información menos cierta a la hora de usarse el subjuntivo:

2a) Tal vez mi vecina tenga novio. 2 b) Tal vez mi vecina tiene novio.

En el ejemplo 2a) el distanciamiento del hablante hacia su mensaje es mayor, ya que se sobreentiende La verdad es que no creo que tenga novio. A su vez, el 2b) se convierte en un dato altamente probable, aunque no del todo confirmado, debido al uso de tal vez.

Otra manera de expresar lingüísticamente el distanciamiento hacia el contenido del mensaje es el empleo de los denominados tiempos de probabilidad. Según Rojo y Veiga [1999: 2894-2895] se trata de ciertas temporalidades que, en algunas ocasiones, pierden su valor temporal primario; su valor dislocado supone un cambio modal. Este es el caso del futuro de indicativo, entre otros, que en su valor recto expresa posterioridad respecto al punto cero de las relaciones temporales ${ }^{1}$. No obstante, en ocasiones se utiliza en referencia a acontecimientos simultáneos al punto cero y es entonces cuando se convierte en una expresión de probabilidad. De esta manera y en determinadas circunstancias ${ }^{2}$, al decir:

${ }^{1}$ Principalmente dicho punto coincide con el ahora de la situación enunciativa en cuestión.

${ }^{2}$ Si el futuro se usa en su valor primario el enunciado Mi vecina tendrá novio presupone que la vecina en cuestión todavía no tiene pareja pero que, dentro de algún tiempo, dicha situación cambiará. 
3) Mi vecina tendrá novio.

el hablante transmite en realidad el siguiente mensaje: No sé exactamente pero me parece que mi vecina tiene novio.

Tanto el futuro como otras formas que se usan con valor de probabilidad (cantaría, habré cantado y habría cantado), no están adscritas a un tipo de discurso determinado, pero sí lo está el llamado condicional de rumor. Se trata de la forma cantaría, utilizada en textos periodísticos para hacer referencia a información incierta o no suficientemente documentada [Agencia EFE, 2008: 78], como en el siguiente ejemplo:

4) El presidente estaría buscando otra salida a la crisis.

Asimismo, las preguntas en las que se emplean los tiempos de probabilidad conllevan un matiz de distanciamiento mental por parte del hablante frente a los demás participantes de la situación comunicativa y, en particular, al destinatario del mensaje. A diferencia de otras preguntas, en las formuladas con los tiempos de probabilidad no se espera una respuesta: se trata más bien de manifestar las emociones que acompañan a las circunstancias. Eso es lo que ocurre con los siguientes enunciados:

5a) ¿Dónde habrás metido tus llaves? o 5b) ¿Dónde estará y qué hará ahora mi mejor amiga del instituto?

con los que el hablante no espera obtener una respuesta a su pregunta. De ser así, habría preguntado:

6a) ¿Dónde has metido tus llaves? 6b) ¿Dónde está y qué hace ahora mi mejor amiga del instituto?

En el ejemplo 5a) el emisor del mensaje, al no encontrar las llaves o al esperar inútilmente que alguien las encuentre, expresa su impaciencia, rabia u otro sentimiento negativo provocado por tal situación; en el 5b) manifiesta su nostalgia por los tiempos pasados. Contrariamente a las preguntas tradicionales, en las que se buscan respuestas, en el caso de las preguntas con los llamados tiempos de probabilidad, la presencia de un posible interlocutor es completamente innecesaria. 
En teoría, el emisor del mensaje podría evitar formular verbalmente sus preguntas pero al hacerlo en voz alta consigue el efecto emocional anteriormente escrito.

El segundo tipo de distanciamiento hacia su propio mensaje se debe a la obvia razón de que el hablante se sirve de palabras ajenas y, además, ve la necesidad de indicarlo de alguna manera. Fernández Lagunilla [1999: 27] distingue entre el hablante en calidad de emisor físico del mensaje, el hablante como ser del discurso y los enunciadores, como los llama la autora, cuyas palabras se manifiestan por intermediación del hablante discursivo.

La presencia de un locutor que no sea el emisor del mensaje se hace patente gracias a cuatro métodos discursivos, descritos por Fuentes Rodríguez [2007: 49]. El primero consiste en introducir en el enunciado un complemento locutivo en forma de una oración o un sintagma con expresiones de habla, como en términos de...; en palabras de ...; como dice...; según afirma ...; según explicó... Es un recurso muy frecuente en textos científicos o periódicos:

7) La primera fase del proyecto empezará el próximo año, según afirma el presidente de la compañia.

El segundo modo de marcar la existencia de un locutor consiste en el uso del estilo directo, es decir, una reproducción literal de un enunciado, cuya finalidad consiste en «marcar diversidad de situación enunciativa» [Fuentes Rodríguez 2007: 53]. El autor llama a este tipo de enunciados enunciados parentéticos.

8) «Mi objetivo es comenzar el año que viene con la etapa inicial del proyecto», dijo ayer en la rueda de prensa el presidente de la compañia.

El tercer modo de manifestar la presencia de un locutor, es el discurso indirecto. A diferencia de las citas directas, en este caso, el hablante hace suyo el discurso de otro, aplicando las correspondientes modificaciones deícticas [Fuentes Rodríguez 2007: 50- 51]. Véase el siguiente ejemplo: 
9) El presidente de la compañia dijo ayer en la prensa que su objetivo era comenzar el año que viene con la etapa inicial del proyecto.

Por último, el cuarto método para la distinción entre el locutor y el enunciador puede realizarse por medio de los complementos de aserción, según la terminología utilizada por Fuentes Rodríguez [2007: 54]. Contrariamente a lo que ocurre en los anteriores métodos, en este, es el hablante quien asume el papel de locutor, mientras que el sujeto de la construcción complementaria hace las veces del enunciador, es decir, la persona que se responsabiliza por el mensaje transmitido. En la mayoría de los casos son construcciones precedidas por la palabra según (como: según las fuentes), reforzadas por el uso de algún tiempo de probabilidad (este sería...) 3 $^{3}$.

10) Según las fuentes, la primera etapa del proyecto empezaría el año que viene.

En los mencionados casos se suele dar el nombre del autor de las palabras aducidas e incluso su función, profesional o social, que le faculta para presentar una determinada opinión. El objetivo del emisor del mensaje consiste principalmente en fundamentar y argumentar sus propias teorías; por ello, los métodos que acaban de describirse son típicos de textos que requieren pruebas de credibilidad, como son los textos periodísticos o científicos.

En otro tipo de textos, los motivos por los que el hablante opta por apoyarse en enunciados ajenos no tienen nada que ver con la credibilidad; en consecuencia, no se facilitan los datos de su autor. La intención del emisor del mensaje es la de diluir la responsabilidad de lo que se dice, debido a que la seguridad de la noticia no es suficiente, el hablante no está conforme con la información comentada o, simplemente, no puede revelar la fuente del mensaje al tratarse de una noticia de algún modo comprometida. En tales circunstancias, se tiende a utilizar las formas impersonales se dice o dicen ${ }^{4}$ :

${ }^{3}$ El empleo de la forma "cantaría" no es otro que el condicional de rumor, anteriormente descrito.

${ }^{4}$ Pueden emplearse también otros verbos de comunicación. 
11a) Se dice/ se comenta que mi vecina tiene novio. 11b) Dicen que mi vecina tiene novio.

\section{Distanciamiento aparente}

Además de las medidas lingüísticas por las que el hablante puede manifestar su distanciamiento hacia el mensaje transmitido, existe toda una serie de recursos de naturaleza deíctica u ocasionalmente deíctica que permiten al emisor del mensaje expresar sus opiniones personales como si fueran de otra persona, o lo que es lo mismo, ofrecen la posibilidad de distanciarse frente al yo de la situación comunicativa.

En primer lugar, en vez de utilizar la forma yo, el emisor del mensaje puede decidirse por una solución intermedia, esto es, la forma nosotros, que incluye el concepto de yo. El concepto de nosotros, que cubre el campo de yo + tú, o yo + vosotros/vosotras se suele llamar plural inclusivo, ya que se refiere también al destinatario del mensaje; mientras que yo + él/ella/ellos/ellas se denomina plural exclusivo, dado que excluye el $t u^{5}$.

Por una parte, el emisor del mensaje se sirve del plural inclusivo para difuminar el concepto de yo y presentar así una opinión más personal, convirtiéndola en una compartida por el destinatario del mensaje. Hernández Sacristán [1995: 491-492] llama a este empleo plural cooperativo, calificándolo de uso ficcional del plural inclusivo, referencialmente no motivado, dado que incluye al interlocutor, mientras que, en realidad, se trata de una referencia al autor del mensaje. Hernández Sacristán menciona dos finalidades por las que el hablante recurre a dicho uso del plural: distribución de la responsabilidad por lo dicho entre el emisor del mensaje y el destinatario del mismo o la

${ }^{5}$ A falta de marcas morfológicas de exclusividad o inclusividad, en la mayoría de los casos las sugerencias al respecto tienen que buscarse en el contexto [Nowikow, 1994: 286]. 
intención de hacer más activa la presencia del receptor gracias a su inclusión en la construcción discursiva. Dicho fenómeno se observa a menudo en discursos políticos. Véase el siguiente ejemplo:

12) Tenemos que encontrar una solución a estos problemas si queremos mantener el ritmo de las reformas.

Por otra parte, el plural exclusivo también tiene su variante ficcional, esto es, un uso referencial no motivado ya que, en realidad, se trata de una autorreferencia [Hernández Sacristán, 1995: 481-482]. Hablamos del denominado plural de modestia, cuya función comunicativa consiste en "enmascarar la expresión de autorreferencia" [Hernández Sacristán, 1995: 484] pero, además, tiene un valor simbólico, que "pretende difuminar la autorreferencia simbolizando connotativamente que el ego del autor se disuelve en un colectivo de referencia indefinida, pero del que está excluido, en cualquier caso, el lector" [Hernández Sacristán, 1995: 485]. En otras palabras, el plural de modestia es una manera de presentar una opinión propia como si fuera la opinión de un mayor número de personas. Así, el hablante resta importancia a su papel en la autoría de la misma, lo cual puede tener origen en la falta de voluntad de imponer su punto de vista, sentenciar algo de forma demasiado tajante, poca seguridad respecto a lo que se dice o, como sugiere la denominación del referido recurso discursivo, conciencia de que es más prudente exponer sus teorías antes que exponer su persona. El plural de modestia se utiliza principalmente en trabajos científicos. Véase el enunciado que sigue:

13) Creemos que el distanciamiento del hablante se manifiesta en varias construcciones lingüísticas.

En segundo lugar, otra manera de disimular el yo del mensaje consiste en emplear la forma tú para realizar una autorreferencia. Se aplica en situaciones en las que el hablante se distancia de su propio enunciado ya que quiere que su interlocutor se sienta identificado con las experiencias que se le están contando.

14) Tienes buenas intenciones y luego resulta que nadie te cree. 
En tercer lugar, es preciso mencionar igualmente dos situaciones más en las que el hablante se distancia de sí mismo, esta vez sin servirse de los elementos deícticos. Por una parte, están los enunciados en los que el sujeto del verbo conjugado en tercera persona es el servidor y, por otra, los enunciados en los que el sujeto es uno o una, según sea el sexo del emisor del mensaje. Véanse los siguientes casos:

15) No te preocupes. No irás sola al baile de fin de curso porque te acompañará un servidor.

16) Una no deja nunca de preocuparse por sus hijos, ni siquiera cuando se hacen mayores.

\section{Conclusiones}

Hemos clasificado los recursos de distanciamiento utilizados por los hablantes de español en dos grupos. En el primer caso, el distanciamiento es explícito, debido a que el hablante señala su escasa seguridad en relación con el contenido del mensaje (construcciones de probabilidad) o falta de identificación con el mismo, que, al fin y al cabo, puede resultar aparente (referencia, también literal, a palabras de otras personas). En el segundo caso, el distanciamiento es aparente ya que se trata de eliminar las marcas personales en mensajes con autorreferencia.

Sea cual sea la forma elegida, son diversas las motivaciones que inspiran a los hablantes a la hora de manifestar su distanciamiento frente al mensaje transmitido. No obstante, es posible distinguir un denominador común de todos los casos descritos en el presente artículo. Al distanciarse de su mensaje o de sí mismo, el emisor deja a su interlocutor sin posibilidad de expresar su postura frente a la información recibida: no puede discutir con los contenidos transmitidos mediante las formas de probabilidad, ni contestar a las preguntas formuladas en tiempos de probabilidad, ni tampoco enfrentarse directamente a los mensajes procedentes de alguien que no sea su emisor 
y, además, mediante modificaciones deícticas se le adscriben opiniones u experiencias ajenas. Dicho de otra manera: a raíz de los recursos de distanciamiento utilizados por el hablante, el destinatario del mensaje tiene asignado un papel pasivo en el proceso de comunicación.

\section{Bibliografía}

AGENCIA EFE (2008), Manual de español urgente, Cátedra, Madrid.

FERNÁNDEZ LAGUNILLA, M. (1999), La lengua en la comunicación politica I: El discurso del poder, Arco/Libros, Madrid.

FUENTES RODRÍGUEZ, C. (2007), Sintaxis del enunciado: los complementos periféricos, Arco/Libros, Madrid.

HERNÁNDEZ SACRISTÁN, C. (1995), "Deíxis social y cortesía en textos científicos: un estudio contrastivo", Verba, 22, pp. 477-500.

NOWIKOW, W. (1994), "Sobre la pluralización de personas gramaticales en las lenguas románicas: nōs, vōs/ nōsalterōs, vōsalterōs", Anuario de Lingüistica Hispánica, 10, Valladolid, pp. 283-300.

ROJO, G., VEIGA, A. (1999), "El tiempo verbal. Los tiempos simples", en: Bosque, I., Demonte, V. (eds.), Gramática descriptiva de la lengua española, vol. 2, Espasa, Madrid, pp. 2867-2934. 